\title{
Antibiotic Resistance: Practices and Management
}

\author{
S. Solanki* and Durga Devi \\ Department of Veterinary Microbiology and Dept. of Livestock Farm Complex, College of \\ Veterinary Animal Science, Navania, Vallabnagar-313601, Udaipur, India \\ *Corresponding author
}

\section{A B S T R A C T}

\begin{tabular}{l} 
K e y w o r d s \\
$\begin{array}{l}\text { Antibiotic } \\
\text { resistance, } \\
\text { Knowledge, } \\
\text { Rational use }\end{array}$ \\
Article Info \\
$\begin{array}{l}\text { Accepted: } \\
20 \text { August } 2020 \\
\text { Available Online: } \\
10 \text { September } 2020\end{array}$ \\
\hline
\end{tabular}

\begin{abstract}
Antibiotics are the 'beautifully made drugs' to combat microorganisms. For decades, various varieties of antibiotics have not only been used for therapeutic purposes but practiced prophylactically across many industries such as agriculture and animal husbandry. Uncertainty has arisen, as microbes have become resistant to common antibiotics while the host remains unaware that antibiotic resistance has emerged. The aim of this review is to explore the origin, development, and the current state of antibiotic resistance, regulation, and challenges by examining available literature. It was found that antibiotic resistance is increasing at an alarming rate. A growing list of infections like MRSA is becoming harder and at times impossible to treat while antibiotics are becoming less effective. Antibiotic-resistant infections correlate with the level of antibiotic consumption. Non-judicial and indiscriminate use of antibiotics is mostly responsible for making the microorganism resistant. The antibiotic treatment repertoire for existing or emerging hard-to-treat multidrug-resistant bacterial infections is limited, resulting in high morbidity and mortality report. This review article reiterates the optimal use of antimicrobial medicines in human and animal health to reduce antibiotic resistance. Evidence from the literature suggests that the knowledge regarding antibiotic resistance in the population is still scarce. Therefore, the need of educating patients and the public is essential to fight against the antimicrobial resistance battle.
\end{abstract}

\section{Introduction}

In the past 50 years, antibiotics have been critical in the fight against many diseases and infections. Their discovery was one of the leading causes for the dramatic rise of average life expectancy in the 20th century and their significance to public health would be impossible to overstate. Antibiotics are defined as any compound which either kills or severely impedes the growth of bacteria.
Upon the introduction of penicillin into general clinical practice in 1944, formerly deadly illnesses such as Strep throat and tuberculosis became instantly curable. Today, our dependence on antibiotics is absolute. In 1998, in the United States, it was estimated that there were 80 million prescriptions of antibiotics for human use, the equivalent of about 12,500 tons in one year. When animal and agricultural uses of antibiotics are added to human use, it is estimated that in the past 
50 years, more than 1 million tons have been produced and disseminated.

Almost as soon as antibiotics were introduced into clinical circulation, cases where their ability to effectively stop infection were observed. As the use of antibiotics became more widespread, the prevalence of antibiotic resistant bacteria increased. In a recent study in Atlanta, 25\% of bacterial pneumonia cases were shown to be resistant to penicillin, while a further $25 \%$ of cases were resistant to more than one antibiotic. Resistance development has resulted in perpetual research and development in the search of new antibiotics in order to maintain a pool of effective drugs at all times. While the development of resistant strains is inevitable, the speed and scale of development has been exacerbated by the practices through which we use and disseminate antibiotics.

Resistance to antimicrobials is a natural biological phenomenon. The introduction of every antimicrobial agent into clinical practice has been followed by the detection in the laboratory of strains of microorganisms that are resistant, i.e. able to multiply in the presence of drug concentrations higher than the concentrations in animals receiving therapeutic doses. Such resistance may either be a characteristic associated with the entire species or emerge in strains of a normally susceptible species through mutation or gene transfer. Resistance genes encode various mechanisms which allow microorganisms to resist the inhibitory effects of specific antimicrobials. These mechanisms offer resistance to other antimicrobials of the same class and sometimes to several different antimicrobial classes.

\section{Types of resistance}

Natural resistance: Inherently or genetically resistant due to lake of penetration of drug into bacterial cell, absence of metabolic pathway or target site or rapid inactivation of drug in bacterial cell.

Acquired resistance: Resistance against drug to which bacteria was previously sensitive. It is due to inappropriate use of antimicrobials. It is done by mutation or gene transfer.

\section{Development and acquisition of resistance}

Many infectious diseases have been brought under control around the world yet this remains the leading cause of death in the world. Furthermore, previously controlled infections are becoming increasingly common in patients with diseases like AIDS where the immune system is compromised. The microbes responsible for these infections are often antibiotic resistant pathogens. The ability for the pathogens to grow despite the presence of antibiotics, through the development of antibiotic resistance, has rendered victims as vulnerable as patients from the pre-antibiotic era.

The development of resistance is inevitable following the introduction of a new antibiotic. In fact initial rates of resistance to new drugs are normally on the order of $1 \%$. However modern uses of antibiotics have caused a huge increase in the number of resistance bacteria. In fact within eight to twelve years, after wide spread use, strains resistant to multiple drugs become widespread.

How do bacteria become resistant to antibiotics and what are the biochemical mechanisms that they use? Several mechanisms have been developed by bacteria in order to deal with antibiotics but all require either the modification of existing genetic material or the acquisition of new genetic material.

Originally it was believed that all resistance was acquired through spontaneous mutation. 
Development of resistance through this method is called primary resistance. Errors in DNA synthesis during replication and occasional failures in the DNA repair systems result in a spontaneous mutation frequency for an individual base pair of about 10-7-10-8. This means that for every 107-108 bacteria, we would expect one single base pair to be changed. Mutation is a very rare event. However, the spontaneous mutation rate to acquire a mutation that causes resistance is often even lower since multiple mutations must take place before primary antibiotic resistance can be acquired. In E. coli, it has been estimated that primary streptomycin resistance is acquired at a rate of approximately 10-9 when exposed to high concentrations of streptomycin. While this is an extremely rare event, the very fast growth rate of bacteria means that it doesn't take long before resistance is developed in a population. Once the resistance genes are acquired, the genes can be transferred directly to all the bacteria's progeny. This is known as vertical genetransfer (Table 1-4).

\section{Mechanism of resistance}

Reduced drug accumulation: by decreasing drug permeability and/or increasing active efflux (pumping out) of the drugs across the cell surface

Drug inactivation or modification: e.g., enzymatic deactivation of Penicillin in some penicillin-resistant bacteria through the production of $\beta$-lactamases.

Alteration of target site: e.g., alteration of $\mathrm{PBP}$ - the binding target site of penicillins in MRSA and other penicillin-resistant bacteria.

Alteration of metabolic pathway: e.g., some sulfonamide-resistant bacteria do not require para-aminobenzoic acid (PABA), an important precursor for the synthesis of folic acid and nucleic acids in bacteria inhibited by sulfonamides. Instead, like mammalian cells, they turn to utilizing preformed folic acid.

\section{Consequences of resistance}

The emergence of antimicrobial resistance has an impact on the cost of animal and human health care worldwide. Ineffective therapy due to antimicrobial resistance is associated with increased animal and human suffering, loss of productivity and often death (WHO, 2001). Resistant strains of bacteria are found around the world. Organisms that are resistant to one drug are more likely to become resistant to others. The bacteria Streptococcus pneumonia has become resistant to penicillin and now demonstrates some resistance to several other antibacterials. Resistant pathogens are expensive to control and extremely difficult to eradicate. Ineffective therapy can seriously affect the progress and outcome of disease. It has significant impact the cost of treating disease. Limited clinical effectiveness of readily available cheap antimicrobials in many regions which results in difficult to choice and to use more effective but more expensive drugs to treat. Resistant animal pathogens in food products may cause infections in humans that are difficult to treat. Loss of public confidence in the safety of food which affects the demand for products, with potentially serious economic effects on the farming sector

Practices responsible for failure of antimicrobials in disease state

Improper diagnosis (Viral not Bacterial infection)

Improper selection of drug (Causative organisms are not sensitive to drug).

The microorganisms have developed resistance to drug. Mixed infection \& narrow spectrum drug

Penetration of drug into site infection is not proper due to pus, debris, exudates etc.

The host defense mechanism is impaired

Improper route of administration with 
inadequate duration of treatment

Interaction of drug with other administered drugs.

Late administration of antimicrobial drug

Use of expired drug
The owner or attendant of animal does not comply with therapeutic regimen

Improper nursing and feeding

Table.1 Reports of resistance developed in bacteria from India

\begin{tabular}{|c|c|c|}
\hline Bacteria & Resistance to & Reference \\
\hline $\begin{array}{l}\text { Streptococcus } \\
\text { pneumoniae }\end{array}$ & $\begin{array}{l}\text { Penicillin, cotrimoxazole, tetracycline, erythromycin, } \\
\text { ciprofloxacin }\end{array}$ & $\begin{array}{l}\text { Goyal et al., } 2007 \text { Chawala et } \\
\text { al., } 2010\end{array}$ \\
\hline S. pyogenes & Penicillin, erythromycin, trimethoprim & $\begin{array}{l}\text { Capoor et al., } 2009 \\
\text { Bergmann et al., } 2012\end{array}$ \\
\hline Staphylococcus aureus & Clindamycin, Vancomycin & $\begin{array}{l}\text { Gupta et al., } 2009 \\
\text { Thati } \text { et al., } 2011\end{array}$ \\
\hline E. Coli & $\begin{array}{l}\text { Ampicillin, tetracycline, co-trimazole, } \\
\text { trimethoprime, carbenicillin }\end{array}$ & Sukumaran et al., 2012 \\
\hline Salmonellaspp. & $\begin{array}{l}\text { Nalidixic acid, ciprofloxacin, ampicillin, } \\
\text { chloramphenicol, ampicillin and trimethoprim }\end{array}$ & $\begin{array}{l}\text { Rowe et al., } 1997 \\
\text { Nagshettyet al., } 2010\end{array}$ \\
\hline K. pneumoniae & Ceftizoxime, cefotaxime, carbenicillin & $\begin{array}{l}\text { Sikarwar\& Batra, } 2011 \\
\text { Nagaraj et al., } 2012\end{array}$ \\
\hline Shigella spp. & $\begin{array}{l}\text { Newer gen. fluoroquinolones, 3rd gen. } \\
\text { Cephalosporins }\end{array}$ & Bhattacharya et al., 2012 \\
\hline Pseudomonas spp. & $\begin{array}{l}\text { Ciprofloxacin, ceftazidime, cefepime, } \\
\text { gentamicin, amikacin }\end{array}$ & Chaudhary et al., 2013 \\
\hline
\end{tabular}

Table.2 Type, mode and spectrum of activity of different antimicrobial agents

\begin{tabular}{|l|l|l|l|}
\hline $\begin{array}{c}\text { Group of } \\
\text { antimicrobials }\end{array}$ & $\begin{array}{c}\text { Type of } \\
\text { action }\end{array}$ & \multicolumn{1}{|c|}{ Mode of action } & $\begin{array}{c}\text { Spectrum of } \\
\text { activity }\end{array}$ \\
\hline Penicillins & Bactericidal & Inhibition of cell wall synthesis & Narrow \\
\hline Cephalosporins & Bactericidal & Inhibition of cell wall synthesis & Broad \\
\hline Carbapenems & Bactericidal & Inhibition of cell wall synthesis & Broad \\
\hline $\begin{array}{l}\text { Polypeptide } \\
\text { Antibacterials }\end{array}$ & Bactericidal & Inhibition of cell wall synthesis & Narrow \\
\hline Quinolones & Bactericidal & Inhibits DNA synthesis & Broad \\
\hline Metronidazole & Bactericidal & Inhibits DNA synthesis & Narrow \\
\hline Rifamycins & Bactericidal & Inhibitions of RNA transcription & Narrow \\
\hline Aminoglycosides & Bacteriostatic/ & Inhibition of protein synthesis & Narrow \\
\hline Lincosamides & Bactericidal & & Narrow \\
\hline Macrolides & Bacteriostatic & Inhibition of protein synthesis & Narrow \\
\hline Tetracyclines & Bacteriostatic & Inhibition of protein synthesis & Broad \\
\hline Chloramphenicol & Bacteriostatic & Inhibition of protein synthesis & Broad \\
\hline Sulfonamides & Bacteriostatic & Inhibition of protein synthesis & Broad \\
\hline
\end{tabular}


Table.3 Spectrum of activity of commonly used antimicrobials

\begin{tabular}{|l|l|l|}
\hline G+ve activity & G-ve activity & Anaerobic activity \\
\hline Penicillins & Fluoroquinolones & Penicillins \\
\hline Macrolides & Aminoglycosides & Metronidazole \\
\hline Cephalosporins & Cephalosporins & Cephalosporins \\
\hline Sulpha + TMP & Sulpha + TMP & Sulpha + TMP \\
\hline OTC & OTC & OTC \\
\hline Imipenem & Imipenem & Imipenem \\
\hline Chloramphenicol & Chloramphenicol & Chloramphenicol \\
\hline Rifampin & & Clindamycin \\
\hline
\end{tabular}

Table.4 Last-resort antibacterials

\begin{tabular}{|l|l|}
\hline Drug & Why last resort? \\
\hline 1) Meropenem and other carbapenem & Potency \& lack of resistance \\
\hline 2) Vancomycin & Anti-MRSA \\
\hline 3) Co-trimoxazole & Powerfull \\
\hline 4) Piperacillin/Tazobactam & Broad coverage \\
\hline 5) Levofloxacin & Broad spectrum\& PO \\
\hline 6) Linezolid & Anti-MRSA \\
\hline 7) Cefepime & Broad spectrum \\
\hline 8) Polymyxin B (Colistin) & Potent \\
\hline 9) Tigecycline & Anti-MRSA \\
\hline 10) Aztreonam & Anti-pseudomonal \\
\hline
\end{tabular}

Management of the Resistance Problem How can we select antibiotics?

Requires clinical judgment and detailed knowledge of pharmacological and microbiological factors.

Antibacterials: empirical therapy, definitive therapy, and prophylactic therapy.

Empirical therapy: infecting organism has not been identified - Combination therapy/broad-spectrum agent

Infecting microorganism is identified : Narrow-spectrum AB

Select an antibacterial based on indication

The diagnosis may be masked if therapy is started before cultures are obtained.

Antibacterials may be used immediately if disease is severe

Initiation of optimal empiric antibacterial therapy: knowledge of most likely infecting organisms and their antibacterial susceptibilities.

Simple and rapid laboratory tests may permit more rational selection of initial antibacterial therapy.

Blood should be taken prior to the institution of drug therapy.

For definitive therapy, Use specific \& narrowspectrum antibacterial once an organism has been identified \& its susceptibility is known. 


\section{Successful Antimicrobial Therapy depends on}

For definitive therapy, recommend a narrowspectrum drug

Keep the broad spectrum drug reserve for life threatening infection

Prefer bactericidal over bacteriostatic drug with less toxicity

Prefer drug requires administration at long interval

For less severe infections prefer an oral administration in small animals

For $\quad$ severe $\quad$ infection $\square \quad$ parenteral administration

Always use antimicrobial agent in proper dose

Proper duration of time

Do not combine antimicrobials without valid cause

Do not use antimicrobial indiscriminately

Avoid overuse of newer agent if older is effective

Use drug manufactured by reliable pharmaceutical firm.

Do not use antimicrobials to treat slight, selflimiting or unbeatable infections.

\section{How can we fight back?}

Maintain good hygiene and infection control measures - particularly hand washing.

Strict infection control measures should be monitor in hospitals

Don't use antibacterial in minor or self limiting viral infections

Farmers should not use antibacterials of previous prescription

Educate farmers: help them to understand about cost of unnecessary use of antibacterials

Communicate with farmers about progression of disease after initiation of therapy

Use laboratory tests to support your diagnosis $\&$ select the right antibacterial.

Record of vaccinations must be generated.
Develop and implement guidelines, protocols and drug utilization reviews to ensure that use of antibacterial drug I optimized

Ensure surveillance for changes in the occurrence and pattern of antimicrobial resistance in different bacteria.

Emphasise good animal husbandry practices (adequate and clean quarters)

Work with governments to move away from using antibacterials as growth promoters.

Collaborate in monitoring of antibacterial use and resistant pattern within stitutes

Educate the public and health professionals about the antibacterial resistance

Coordinate the development and implementation of regional programs to optimize antibacterial use and to prevent the spread of resistant organisms.

Develop the rapid affordable systems for diagnosis and susceptibility testing.

Ensure that antibacterials remain available through prescription only, rather than as over-the-counter medications.

\section{References}

Adams, H.R. (2001). Veterinary Pharmacology and Therapeutics. $8^{\text {th }}$ Edn. Iowa Stae Uni.

Press., Iowa.

Archana Singh Sikarwar and Batra, H.V.. (2011). Prevalence of Antimicrobial Drug Resistance of Klebsiella pneumoniae in India. International Journal of Bioscience, Biochemistry and Bioinformatics, 1: 21115

Rowe, B., Ward, L.R. and Threlfall, E.J. (1997). Multidrug-Resistant Salmonella typhi: A Worldwide Epidemic. Clinical Infectious Diseases, 24(Suppl 1):S106-9.

Bhattacharya D., Sugunan A.P., Bhattacharjee H., Thamizhmani R., Sayi,D.S., Thanasekaran, K., Manimunda, S.P., Ghosh, A.R., Bharadwaj, A.P., Singhania, M., Roy, S. (2012). Antimicrobial 
resistance in Shigella--rapid increase \& widening of spectrum in Andaman Islands, India. Indian J MedRes., 135:365-70.

Capoor ,M.R., Nair, D., Deb, M., Batra, K., Aggarwal, P. (2006). Resistance to erythromycin and rising penicillin $\mathrm{MIC}$ in Streptococcus pyogenes in India. Jpn J Infect Dis., 59(5): 334-6.

Sukumaran, D.P., Srinivasan, D., and Abdulla, M.H. (2012). Antibiotic Resistance of Escherichia coli Serotypes from Cochin Estuary. Interdisciplinary Perspectives on Infectious Diseases. Article ID 124879, 7 pages.

Goyal, R., Singh, N.P., Kaur, M., Talwar, V. (2007). Antimicrobial resistance in invasive and colonizing Streptococcus pneumoniae in North India. Indian J Med Microbiol., 25(3):256-9.

Gupta, V., Datta, P., Rani, H., Chander, J. (2009). Inducible clindamycin resistance in

Staphylococcus aureus: a study from North India. J Postgrad Med., 55(3):176-9.

Renuka, K., Sood, S., Das, B.K. and Kapil, A. (2005). High-level ciprofloxacin resistance inSalmonella enterica serotype Typhi in India. J Med Microbiol., 54:999-1000.

Nagshetty, K., Channappa, S.T. and Gaddad, S.M. (2010). Antimicrobial susceptibility of Salmonella Typhi in India. J Infect Dev Ctries., 4:070-073.

Chawla, K., Gurung, B., Mukhopadhyay, C. and Bairy, I. (2010). Reporting Emerging Resistance of Streptococcus pneumoniae from India. J Glob Infect Dis. 2(1): 10-14.

Li, X. and Nikadio H (2009). "EffluxMediated Drug Resistance in Bacteria: an
Update". Drug 69 (12):1555-623.

Nagaraj, S, Chandran, S.P., Shamanna, P., Macaden, R. (2012). Carbapenem resistance among Escherichia coli and Klebsiella pneumoniae in a tertiary care hospital in south India. Indian $J$ Med Microbiol. 30:93-5.

René Bergmann,Vivek Sagar,D. PatricNitsche-Schmitz and Chhatwal, G.S. (2012). First Detection of Trimethoprim Resistance Determinant dfrG in Streptococcus pyogenes Clinical Isolates in India. Antimicrob. Agents Chemother., 56: 105424-5425.

Sandhu, H.S. (2013). Chemotherapy. In Essentials of Veterinary Pharmacology and Therapeutics. $2^{\text {nd }}$ Edn. Kalyani Publishers. New Delhi. Pg. No. 897-916.

Thati, V., Shivannavar, C.T. and Gaddad, S.M. (2011). Vancomycin resistance among methicillin resistant Staphylococcus aureus isolates from intensive care units of tertiary care hospitals in Hyderabad. Indian J Med Res. 134: 704-708.

Chaudhari, V., Gunjal, S., Mehta, M. (2013). Antibiotic Resistance Patterns OfPseudomonas aeruginosa In A Tertiary Care Hospital In Central India. International Journal of Medical Science and Public Health, 2: 386-89.

WHO (2001). WHO Global Strategy for Containment of Antimicrobial Resistance. Available at http://www.who.int/csr/resources/publicati ons/drugresist/en/EGlobal_Strat.pdf

\section{How to cite this article:}

Solanki, S. and Durga Devi. 2020. Antibiotic Resistance: Practices and Management. Int.J.Curr.Microbiol.App.Sci. 9(09): 2982-2988. doi: https://doi.org/10.20546/ijcmas.2020.909.367 